\title{
POTENCIALIDADE DAS REDES SOCIAIS E DOS RECURSOS IMAGÉTICOS PARA A DIVULGAÇÃO CIENTÍFICA EM PERIÓDICOS DA ÁREA DE CIÊNCIA DA INFORMAÇÃO
}

\author{
Célia da Consolação Dias \\ Professora do Departamento de Organização e Tratamento \\ da Informação da Escola de Ciência da Informação da \\ Universidade Federal de Minas Gerais (UFMG). \\ celiadias@gmail.com \\ https://orcid.org/0000-0003-0891-6454
}

\author{
Rafael Gonçalves Dias \\ Mestre em Ciência da Informação pelo Programa de \\ Pós-Graduação em Gestão e Organização do \\ Conhecimento (PPGGOC) da Universidade Federal de \\ Minas Gerais (UFMG). \\ rafaeldiasufmg@hotmail.com \\ https://orcid.org/0000-0002-6236-5844 \\ Jorge Santa Anna \\ Mestre em Gestão e Organização do Conhecimento, \\ Programa de Pós-graduação em Gestão \& Organização \\ do Conhecimento da Universidade Federal \\ de Minas Gerais (UFMG). \\ professorjorgeufes@gmail.com \\ https://orcid.org/0000-0002-0709-3639
}

\section{RESUMO}

Diante das mudanças no processo de comunicação científica, provocadas pela internet, a ampliação do acesso ao conhecimento científico vem sendo mais demandada pela sociedade, embora esse processo ainda se restrinja a comunidades específicas. Assim, propõe-se identificar o uso de redes sociais e de recursos imagéticos na comunicação científica e adotados por periódicos científicos da área de Ciência da Informação com intuito de apresentar dados sobre o atendimento dessa nova demanda. Foi realizado um estudo documental em websites de 14 periódicos científicos da Ciência da Informação. Constatou-se o uso de redes sociais como estratégia de divulgação científica, embora possa se destacar que os periódicos poderiam utilizar mais recursos midiáticos e imagéticos para aumentar a visibilidade das pesquisas divulgadas.

Palavras-chave: Comunicação científica. Divulgação científica. Periódicos científicos. Redes sociais e recursos imagéticos. Ciência da Informação.

\section{POTENTIALITY OF SOCIAL NETWORKS AND IMAGETIC RESOURCES FOR SCIENTIFIC DISSEMINATION IN INFORMATION SCIENCE PERIODICS}

\begin{abstract}
In view of the changes in the scientific communication process caused by the internet, the expansion of access to scientific knowledge has been more demanded by society, although this process is still restricted to specific communities. Thus, it is proposed to identify the use of social networks and image resources in scientific communication and adopted by scientific journals in the area of Information Science in order to present data on meeting this new demand. A documentary study was carried out on the websites of 14 scientific journals in Information Science. The use of social networks as a strategy for scientific dissemination was found, although it can be highlighted that the journals could use more media and imagery resources to increase the visibility of the published research.
\end{abstract}

Keywords: Scientific communication. Scientific divulgation. Scientific journals. Social networks and image resources. Information Science. 


\section{INTRODUÇÃO}

A Ciência da Informação $(\mathrm{Cl})$ vem se ocupando, cada vez mais, com o valor atribuído à informação, ocorrência predominante na atual sociedade, sobretudo com o uso dos recursos digitais e midiáticos, que redefinem as atividades sociais. Nesse contexto, a atividade científica também é impactada, visto que a informação disseminada, com maior frequência, possibilita mudanças nos processos de produção, de comunicação e de uso da informação, como mencionado por Le Coadic (2004).

Em se tratando de informação científica, deve-se considerar que ela representa uma variável relevante no nível estratégico da ciência e seu insumo contribui para a evolução e o crescimento da sociedade. Esses aspectos são corroborados por Kuramoto (2006, p. 91), ao afirmar que a informação científica "é o insumo básico para o desenvolvimento científico e tecnológico de um país". Isto é, aquele tipo de informação, resultado das pesquisas científicas, normalmente disseminada à comunidade, por meio de periódicos, livros e eventos acadêmicos. Da mesma forma, Targino e Torres (2014) acreditam que a comunicação do que é produzido, no âmbito científico e tecnológico, tem efeito imensurável na construção do conhecimento e no desenvolvimento de uma nação.

Pesquisas apontam que o processo de comunicação científica vem sofrendo alterações e passando por novos desafios, em especial com o uso da internet. Um desses problemas, por exemplo, diz respeito ao fluxo das atividades decorridas durante o processo de validação de uma pesquisa. Fonseca Júnior et al. (2019) mencionam algumas transformações, como: o surgimento dos periódicos digitais, a criação de repositórios da web e a discussão mundial sobre o acesso livre à informação científica. Para Príncipe (2013), a ascensão da web ampliou os tipos de recursos utilizados para esse fim,ao introduzir uma série de possibilidades, como o uso de blogs e de redes sociais para disseminar informação científica.

Diante dessas mudanças, destaca-se, também, o desafio na criação de mecanismos de avaliação de desempenho que atestem a produção ou o volume de acesso à produção científica de instituições de pesquisa. Esses mecanismos podem ser direcionados às instituições que produzem, avaliam ou financiam as pesquisas, como abordado no estudo de Fonseca Júnior et al. (2019). As universidades públicas brasileiras, por exemplo, inserem-se nesse contexto, assim como as agências de fomento e as instituições responsáveis pela manutenção dos canais de comunicação científica, como os periódicos. 


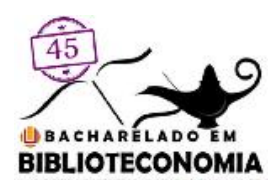

Em linhas gerais, essas instituições possuem a responsabilidade em se adequar ao uso de recursos, que possibilitem uma maior disseminação do conhecimento.

Dentre os mecanismos utilizados por essas instituições que possibilitem uma maior divulgação dos resultados das pesquisas com a sociedade, a literatura tem sinalizado alguns estudos, que indicam o potencial das redes sociais e dos recursos imagéticos de informação. O Facebook (GODEIRO; SERAFIM, 2013), o Twitter (SANTANA JÚNIOR et al., 2014), o Instagram (RIBEIRO; SILVA, 2019) e o YouTube (MURIEL-TORRADO; GONÇALVES, 2018) são alguns tipos de mídias abordadas nos estudos científicos. Além destas, alguns estudos indicam a importância do uso de recursos imagéticos variados, que podem ser utilizados na arquitetura do website de um periódico, possibilitando uma melhor visibilidade. (MONERAT; ROCHA, 2017).

Em função do quadro apresentado, cujas tecnologias de informação proporcionaram novas maneiras de comunicação científica, como uso de redes sociais e imagens, ainda não se tem muita clareza ou dados sobre como esses recursos têm sido explorados na área de Cl. Portanto, neste artigo, propõe-se, como objetivo geral, identificar o uso de redes sociais e recursos imagéticos na comunicação científica, adotados por periódicos científicos da área de Cl. Para tanto, definiram-se como objetivos específicos: esclarecer alguns conceitos referentes ao processo de comunicação científica; fornecer informações sobre o nível de uso de redes sociais e imagens na divulgação científica; e levantar os periódicos dessa área indexados na Scientific Electronic Library Online (SciELO).

\section{COMUNICAÇÃO OU DIVULGAÇÃO CIENTÍFICA?}

As atividades de produção científica são responsáveis pela geração de conhecimentos que, posteriormente, são disseminados, por meio de processos estabelecidos na comunicação científica. O conjunto desses processos é comumente chamado de comunicação e divulgação científica, conceitos que se misturam, cada vez mais. No contexto da comunicação e da divulgação científica, a internet tem sido uma facilitadora do acesso à informação.

Caribé (2015) argumenta a favor da importância do esclarecimento conceitual de termos científicos, segundo o qual, o entendimento e a comunicação de qualquer disciplina ou ciência dependem de sua terminologia. A terminologia, esclarece Cabré (1995, p. 12), "é a peça chave dos especialistas, que sem os termos não poderiam expressar 
nem comunicar seus conhecimentos". Caribé (2015) discute e esclarece o conceito de comunicação científica, termo com sentido muito amplo e que abarca vários processos de comunicação, com finalidades distintas. Sobre a necessidade de se esclarecer, conceitualmente, o significado de comunicação e divulgação científica, pode-se ter como base a seguinte indagação de Bueno (2010, p. 2): “a comunicação científica e a divulgação científica se confundem, ou seja, podem ser consideradas como expressões ou conceitos que designam o mesmo objeto?”. De acordo com Caribé (2015), a resposta seria não, pois a comunicação científica, de forma genérica, é um termo com sentido amplo, e compreende diversas formas de comunicação, que variam de acordo com o tipo de linguagem utilizada ou com o tipo de entidade do processo de comunicação, ao qual se encontra relacionado. "Incorpora tanto a comunicação interna dirigida à comunidade científica quanto a externa, destinada ao público leigo". (CARIBÉ, 2015, p. 101).

Em uma abordagem mais específica, de acordo com Bueno (2010, p. 2), a distinção entre tipo de linguagem e público-alvo (leigo e especialista) está associada aos termos comunicação e divulgação científica, os quais possuem definições específicas:

A divulgação científica compreende a utilização de recursos, técnicas, processos e produtos (veículos ou canais) para a veiculação de informações científicas, tecnológicas ou associadas a inovações ao público leigo. A comunicação científica, por sua vez, diz respeito à transferência de informações científicas, tecnológicas ou associadas a inovações e que se destinam aos especialistas em determinadas áreas do conhecimento. (BUENO, 2010, p. 2).

Diante da definição de Bueno (2010), verifica-se que as principais diferenças entre comunicação e divulgação científica estão associadas a quatro elementos:

- Público-alvo - A divulgação científica se direciona ao público leigo, enquanto a comunicação científica diz respeito à transferência de informações aos especialistas.

- Nível do discurso - Na divulgação científica, o discurso precisa ser decodificado para o público leigo. Já na comunicação científica, espera-se que o público já tenha o domínio necessário para compreender um discurso mais metódico e rigoroso.

- Natureza dos canais - A divulgação científica utiliza canais mais informais, como mídias de comunicação de massa e redes sociais. A comunicação científica é mais formal e rigorosa e está restrita a eventos técnico-científicos e a periódicos.

- Intenções - A divulgação científica tem a intenção de democratizar o acesso ao conhecimento científico. A comunicação científica visa à disseminação de informações especializadas entre pares, como avanços obtidos (resultados de pesquisas, relatos de experiências, dentre outras). 
De modo resumido, pode-se concluir que a diferença principal entre comunicação e divulgação científica está no público-alvo e no nível do discurso. Esse discurso pode assumir distintas dimensões, com um público que possui interesses parecidos e que preza pela qualidade do que é produzido, como também um público mais disperso, com interesses também diversos, o que possibilita a popularização do que foi descoberto.

Nesse sentido, conforme apresentado por Caribé (2015), a comunicação científica é um processo amplo, que se desenvolve de modo horizontal e vertical. Na primeira dimensão, tem-se o processo de comunicação e disseminação propriamente dito, cujas atividades são direcionadas a especialistas que comungam de interesses e princípios, formando a comunidade científica. Na dimensão vertical, desenvolve-se o processo de divulgação científica, que é voltado ao público leigo, haja vista tornar o conhecimento científico acessível ao cidadão comum, ampliando o acesso às descobertas científicas.

A dimensão vertical, direcionada às atividades de divulgação, possibilita a popularização do conhecimento na sociedade. (CARIBÉ, 2015). Essa dimensão constituiu o conceito básico, utilizado no presente artigo. Justifica-se essa escolha, tendo em vista que o uso das redes sociais e dos recursos imagéticos são mecanismos utilizados com grande frequência na sociedade moderna. Esses mecanismos, como pontuado por Shimizu (2013), manifestam-se enquanto estratégias de disseminação pelas comunidades científicas, para tornar o conhecimento produzido mais acessível a todos os públicos da sociedade, sejam eles especialistas ou leigos.

2.1 Uso de redes sociais e recursos imagéticos como canais alternativos de divulgação científica

Conforme apontado, há um esforço de trabalho para encontrar novos meios de divulgar o conhecimento científico, de modo que ele alcance um maior público. Nesse sentido, as redes sociais podem contribuir com essa proposta, sendo definidas como ambientes de interação on-line entre os participantes por meio de trocas de mensagens textuais ou com o uso de variados recursos imagéticos. (TOMAÉL, 2007).

De acordo com a revisão de literatura realizada por Santos, Alves e Oliveira (2019), não há um conceito bem definido ou estabelecido sobre informação imagética, embora o termo se autodefina como informação que está contido em imagens. Os exemplos 
mais comuns e mencionados por esses autores para recursos de informação imagética, ou documentos imagéticos são registros de informação, em formato de imagens, como aquelas que são produzidas por aparelhos técnicos, fotografias e vídeos, e por construções manuais, como as pinturas.

Príncipe (2013, p. 197) menciona que, na sociedade atual, as redes sociais "[...] estão presentes em todos os níveis e segmentos da sociedade e, na ciência, não é diferente". As redes sociais possibilitam uma maior interação entre pesquisadores, leitores e editores, além de contribuírem para oferecer mais velocidade na divulgação das pesquisas e de poderem ser utilizadas por diferentes públicos. Conforme Príncipe (2013) destacam-se, como exemplo de redes sociais emergentes, entre o público leigo: Facebook, YouTube, Twitter, entre outras. Já as redes sociais mais utilizadas por acadêmicos são Mendeley e Research Gate.

Shimizu (2013) relata sobre a reunião anual da American Association for the Advancement of Science (AAAS), com a realização de um painel sobre comunicação científica. Nesse evento, os pesquisadores defenderam o uso do Twitter, Facebook, YouTube e outras mídias sociais para a divulgação das pesquisas científicas, visto que tais redes já fazem parte do dia a dia de uma parcela da população. Além disso, Shimizu (2013) apresenta dados expressivos de acesso à internet e a algumas dessas redes sociais. Segundo a autora, a internet ultrapassou os jornais, como a segunda maior fonte de notícias (após a televisão) para o público em geral, nos Estados Unidos. O Facebook apresentou mais de 680 mil atualizações de status compartilhadas por minuto, uma hora de vídeo criado por segundo no YouTube e 4 mil novas postagens no Twitter. Nesse contexto, entende-se que, se cientistas não estão utilizando as redes sociais, é possível que não estejam se comunicando com a maior parte da população. Logo, "a adoção de redes sociais pode fortalecer e aprimorar a comunicação científica, em particular os periódicos científicos, especialmente as brasileiras". (PRÍNCIPE, 2013, p. 212).

O YouTube é uma rede social que ganha, cada vez mais adeptos do universo científico, conforme destacado no estudo de Lopes (2018). Em tal pesquisa, foi verificada a potencialidade do uso dos vídeos na divulgação científica de objetos de arquivo. A autora relata, também, que o YouTube foi utilizado para divulgação de vídeos de eventos científicos, cujas animações, presentes nesse recurso, contribuíram com a quantidade de visualização (acesso), acarretando uma visibilidade muito mais expressiva. 
Diante da literatura revisada, verifica-se a importância de se utilizar as redes sociais, além de outros formatos alternativos, como as imagens, na divulgação científica. Por isso, optou-se por verificar como essas recomendações estão sendo seguidas por periódicos científicos. Assim, será possível cumprir o objetivo principal da pesquisa: identificar práticas de uso de redes sociais e imagens, nos periódicos da área de $\mathrm{Cl}$.

\section{METODOLOGIA}

Este estudo se caracteriza como uma pesquisa pura, visto que a ideia inicial é provocar reflexões sobre um assunto que vem se destacando com a expansão das tecnologias digitais. Ao contrário de uma pesquisa aplicada, sua intenção é satisfazer uma necessidade intelectual, como defende Gil (2019).

A pesquisa é descritiva, de natureza qualiquantitativa, com procedimentos de pesquisa documental, pois levanta informações que identificam um objeto, quantifica dados e os confrontam. Compara-os, ainda, com resultados de outros estudos, além de recorrer ao levantamento de dados secundários, disponibilizados em sites de instituições.

O universo da pesquisa compreende os periódicos científicos que utilizam estratégias para a divulgação científica, cuja amostra se restringiu aos periódicos da área de $\mathrm{Cl}$, indexados na Scientific Electronic Library Online (SciELO). Definiu-se como recorte de pesquisa, a $\mathrm{Cl}$, considerando a contribuição dessa área quanto aos estudos dos fluxos e dos processos de comunicação, que contribuem com a divulgação da ciência na sociedade, como mencionado por Le Coadic (2004).

A escolha pela SciELO se justifica pelas seguintes razões: a importância dessa plataforma no desenvolvimento do acesso aberto como primeira fonte de periódicos indexada no Directory of Open Access Journals (DOAJ) e pela disseminação de pesquisas de alto rigor científico. (FRIGERI, 2014). Destaca-se que a SciELO é uma plataforma que disponibiliza, gratuitamente,o acesso a diversos periódicos científicos e estabelece critérios rigorosos para a admissão e a permanência desses periódicos.

No intuito de facilitar a condução dos procedimentos de pesquisa, dividiu-se o estudo em três etapas, com os seguintes procedimentos, a saber:

Etapa 1: levantamento dos periódicos da área de Cl, presentes na coleção da SciELO;

Etapa 2: identificação do Qualis desses periódicos na Plataforma Sucupira e consulta, no website dos periódicos, quanto ao uso de redes sociais 
por esses meios de comunicação. Redes sociais, neste estudo, são conceituadas, a partir dos fundamentos propostos por Príncipe (2013), ao definirem-nas como plataformas de divulgação e interação com usuários, com vistas a propagar notícias variadas, que ampliam a visibilidade e promovam maior reconhecimento de um indivíduo ou instituição;

Etapa 3: localização e descrição de recursos imagéticos, utilizados pelos periódicos. Considera-se como recursos imagéticos, no âmbito deste artigo, qualquer tipo de recurso, disponibilizado no website, que não esteja no formato textual, contemplando desenhos, esquemas, fluxogramas, vídeos, fotografias, logomarcas, dentre outros, como recomendado no estudo de Monerat e Rocha (2017).

É importante ressaltar, também, que tanto as redes sociais quanto os recursos imagéticos, neste artigo, foram considerados mecanismos alternativos de divulgação científica. Tais mecanismos, como apontado no estudo de Príncipe (2013), têm a finalidade de aproximar a ciência da sociedade.

A partir dos procedimentos requeridos na etapa 3 , os dados quantitativos e qualitativos foram analisados. Em ambos os casos, os dados foram comparados a outros estudos publicados.

\section{RESULTADOS E DISCUSSÃO}

Conforme etapa 1 , identificaram-se 14 periódicos da área de $\mathrm{Cl}$, indexados pela SciELO, cujos endereços eletrônicos foram extraídos, a fim de guiar os procedimentos da pesquisa documental. Esses periódicos se apresentaram no formato eletrônico e estão vinculados a instituições de pesquisa ou universidades, distribuídas entre os seguintes países: África do Sul, Argentina, Brasil, Colômbia, Costa Rica, México, Peru, Portugal e Venezuela.

Por meio da consulta ao website de cada um desses periódicos, foi possível identificar que eles priorizam a veiculação de pesquisas avançadas, desenvolvidas no âmbito acadêmico ou profissional, com resultados que contribuem para o desenvolvimento ou alguma inovação para a $\mathrm{Cl}$, comungando com áreas interdisciplinares. 
$\mathrm{Na}$ etapa 2, o objetivo foi identificar o uso de redes sociais e recursos imagéticos. Após consulta aos websites dos periódicos, verificou-se que a divulgação é realizada por meio do uso de redes sociais, tais como: Facebook, Instagram, Twitter e YouTube. Esse resultado corresponde ao que foi apontado por Vicente, Corrêa e Sena (2015), ao mencionarem que as redes Facebook, Google+, Instagram, LinkedIn, Twitter e YouTube passaram a ser utilizadas no meio acadêmico. Os resultados desse estudo revelaram que o uso dessas redes

[...] pode amplificar [a] função social ao ser utilizada para a divulgação científica, independentemente da segmentação da rede, pois o importante é o encontro com o interagente, é estar presente no ambiente que é comum ao seu público. (VICENTE; CORRÊA; SENA, 2015, p. 16).

No intuito de melhor visualizar os dados de cada periódico, apresenta-se o quadro 1, contendo o nome do periódico e a indicação das redes sociais utilizadas por ele: Facebook, Instagram, Twitter e YouTube.

Quadro 1-Qualis dos periódicos e uso de redes sociais

\begin{tabular}{|c|c|c|c|c|c|}
\hline Periódicos & Qualis $^{1}$ & Facebook & Instagram & Twitter & YouTube \\
\hline Biblios & A1 & link & & link & \\
\hline Cadernos do Arquivo Municipal & & & link & & \\
\hline Ciência da Informação & B1 & & & & \\
\hline Enlace & & & & & \\
\hline E-Ciencias de lalnformación & & & & link & \\
\hline Información, cultura y sociedade & B2 & & & & \\
\hline InvestigaciónBibliotecológica & A1 & link & link & link & link \\
\hline Palabra clave & A2 & link & & & \\
\hline Perspectivas em Ciência da Informação & A1 & & & link & \\
\hline $\begin{array}{l}\text { Revista Interamericana de } \\
\text { Bibliotecología }\end{array}$ & A2 & link & link & link & \\
\hline $\begin{array}{l}\text { South African Journal of Information } \\
\text { Management }\end{array}$ & & & & link & \\
\hline $\begin{array}{l}\text { South African Journal of Libraries and } \\
\text { Information Science }\end{array}$ & & & & link & \\
\hline $\begin{array}{l}\text { The African Journal of Information } \\
\text { and Communication }\end{array}$ & & & & link & \\
\hline Transinformação & $\overline{A 1}$ & link & link & link & \\
\hline
\end{tabular}

Fonte: Dados da pesquisa (2020).

A partir da análise do quadro 1, percebe-se que a maioria dos periódicos (11 periódicos) utiliza alguma rede social como mecanismo de divulgação. Apenas três periódicos não utilizaram nenhuma rede social. A Revista Investigación Bibliotecológica é o único periódico da SciELO, na área da $\mathrm{Cl}$, que explora todos esses recursos

\footnotetext{
${ }^{1}$ A identificação do Qualis foi realizada mediante a consulta à Plataforma Sucupira.
} 


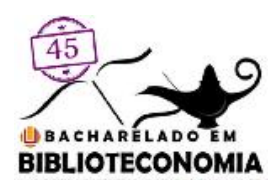

para promover a divulgação científica e ampliar a visibilidade do periódico. Em seguida, Transinformação e a Revista Interamericana apresentaram três das redes sociais analisadas (Facebook, Instagram e Twitter), não utilizando apenas o YouTube.

Esse resultado assemelha-se ao que foi constatado por Souza et al. (2015), quando mencionam que as redes sociais, sobretudo o Facebook, embora constituam importantes ferramentas de divulgação que possibilitam ampliar o acesso às pesquisas científicas, ainda têm sido pouco exploradas pelos periódicos da Cl. Acredita-se, porém, que, por meio do uso de diferentes redes sociais, amplia-se a possibilidade de os resultados das pesquisas serem visualizados, por conseguinte, aumentando-se o número de visitas ao website do periódico. Além disso, segundo Araújo (2019), ao utilizarem diferentes redes sociais, os periódicos se aproximam de outros públicos, que não sejam, necessariamente, especialistas, aumentando a exposição da ciência na websocial.

O mesmo autor defende que as redes sociais possibilitam três importantes contribuições aos periódicos científicos, a saber: 1: a promoção das descobertas científicas; 2: a aproximação do periódico com a comunidade acadêmica e o público leigo; e 3: a avaliação de seu desempenho, quanto às métricas alternativas de acesso, uso e circulação na websocial. (ARAúJO, 2019).

Os dados apresentados no quadro 1 revelam que o Twitter é a rede social mais utilizada (nove periódicos). Em seguida, aparece o Facebook (cinco periódicos), seguido pelo Instagram (quatro periódicos), e, em último lugar, o YouTube, utilizado por um dos periódicos investigados.

Esse resultado não foi corroborado por grande parte da literatura, tais como os estudos de Costa et al. (2016), para o qual o Facebook foi considerado a rede social mais utilizada. Já o estudo de Azevedo et al. (2017) constatou que o Twitter possui maior repercussão, embora tenha sido utilizado mais para fins de entretenimento, do que acadêmico ou científico. A diferença entre os resultados alcançados, neste estudo, sobre o tipo de rede social mais utilizado, e os alcançados com o estudo de Costa et al. (2016) e de Azevedo et al. (2017) pode estar associada ao fato dos segundos analisarem uma amostra maior de periódicos no comparativo com a amostra do primeiro.

O Facebook e o Twitter são apontados como as redes sociais mais utilizadas pelos periódicos de maior qualidade da $\mathrm{Cl}$, indexados pela SciELO. Para Araújo (2018), espera-se que essas redes aumentem, cada vez mais, a visibilidade dos periódicos. O Facebook 
manifesta-se como "[...] instrumento de colaboração e produção de conhecimento, que recomenda, qualifica e dissemina a informação no âmbito da web". (GODEIRO; SERAFIM, 2013, p. 1). Já o Twitter também tem um futuro promissor, sobretudo a partir dos retweets realizados por usuários, que disseminam mensagens criadas por perfis. (SANTANA JÚNIOR et al., 2014).

Embora as redes Instagram e YouTube tenham uma representação menor, no contexto dos periódicos de maior impacto científico da $\mathrm{Cl}$, é importante estudar sobre o uso dessas redes na divulgação científica, em periódicos, observou-se que devido a quantidade expressiva de acessos é importante estudar a potencialidade do uso dessas redes na divulgação científica, em periódicos. O estudo de Ribeiro e Silva (2019) apontou o Instagram como uma importante ferramenta de divulgação de acervos, em especial por disseminar imagens e vídeos, promovendo maior destaque no perfil do periódico na rede social, por conseguinte, aumentando o número de curtidas, e, portanto, elevando-se a exposição na websocial. Por sua vez, Muriel-Torrado e Gonçalves (2018) declaram que o YouTube possibilita o compartilhamento de conteúdo, em audiovisual, relevante para seguidores da rede social.

Mesmo que as redes sociais identificadas ainda não tenham uma repercussão considerável no processo de divulgação científica, como demonstrado neste resultado, não se pode ignorar seu potencial para a divulgação científica. Tal fato é apontado por Costa (2016, p. 38), ao afirmar que os periódicos "[...] devem utilizar as mídias como aliadas para a divulgação do seu produto informação, para reter e atrair leitores, autores e avaliadores, o que consequentemente, amplia a rede de relacionamento [...]".

Importante salientar que o uso das redes sociais, no contexto da produção e disseminação científica, resulta em benefícios, tais como contribui para a disseminação das pesquisas publicadas, ajuda a romper barreiras entre pesquisadores e público não especializado, permite velocidade de disseminação, dentre outros. A ciência vem, cada vez mais, fazendo uso das redes, o que afeta, positivamente, o uso por parte dos periódicos, sobretudo como estratégia de marketing digital. Nesse contexto,

pesquisadores, editores de periódicos científicos ou instituições [de] pesquisa que se interessam em trilhar esse caminho e aproveitar o melhor que essas características oferecem para o emprego do marketing científico digital devem se dedicar a três questões essenciais: construir e manter uma presença online; oferecer um conteúdo adequado aos ambientes que atuar e; estabelecer uma atuação responsiva. (ARAÚJO, 2015, p. 73). 
Embora os resultados, oriundos dessa análise, evidenciem o uso pouco expressivo das redes sociais nos periódicos de alto impacto da $\mathrm{Cl}$, pode-se inferir, pelos relatos da literatura, a importância de se utilizar dessas mídias como uma estratégia a ser adotada por todos os periódicos da área.Além da verificação das redes sociais adotadas pelos periódicos, na etapa 3 deste estudo, procedeu-se à identificação de recursos imagéticos, utilizados para ilustrar o conteúdo dos websites, tornando mais agradável a visualização pelos usuários no ambiente da web.

Ressalta-se que, recursos imagéticos são definidos a partir do que considerou Monerat e Rocha (2017), ou seja, estruturas inseridas em um website que, diferente de estruturas textuais, estimulem os usuários a navegar e conhecer melhor o periódico. Exemplos desses recursos são os desenhos, esquemas, fluxogramas, vídeos, fotografias, logomarcas e outros. Os recursos imagéticos também são caracterizados como as diversas ilustrações, que se apresentam com o uso de figuras, desenhos, objetos coloridos ou incolores, dentre outras tipologias de ilustração. Em algumas áreas do conhecimento, como a Biologia, por exemplo, as imagens são muito utilizadas na divulgação da ciência, como os esquemas, desenhos, gráficos, fotografias, dentre outros. (MONERAT; ROCHA, 2017).

A análise aos websites dos periódicos da $\mathrm{Cl}$ possibilitou a identificação de alguns recursos imagéticos, semelhantes aos apontados no estudo de Monerat e Rocha (2017). O quadro 2 apresenta os recursos utilizados pelos periódicos investigados.

Quadro 2 - Recursos imagéticos utilizados pelos periódicos

\begin{tabular}{|l|l|}
\hline \multicolumn{1}{|c|}{ Periódicos } & \multicolumn{1}{|c|}{ Recursos imagéticos } \\
\hline Biblios & Logomarca de apoiadores; Logomarca do periódico \\
\hline Ciência da Informação & $\begin{array}{l}\text { Capa da edição atual; Capa do periódico; Logomarca da } \\
\text { Licença Creative Commons; Logomarca do Instituto Brasileiro } \\
\text { de Informação em Ciência e Tecnologia (IBICT); Logomarca } \\
\text { do periódico }\end{array}$ \\
\hline $\begin{array}{l}\text { Cadernos do } \\
\text { Arquivo Municipal }\end{array}$ & $\begin{array}{l}\text { Bâneres para chamada de artigos; Capa; Capa dos números; } \\
\text { Indexadores; Logomarca da instituição; Logomarcas das } \\
\text { redes sociais }\end{array}$ \\
\hline $\begin{array}{l}\text { Investigación } \\
\text { Bibliotecológica }\end{array}$ & $\begin{array}{l}\text { Bâneres de notícias; Capas dos últimos números publicados; } \\
\text { Logomarca da instituição; Logomarca da Licença Creative } \\
\text { Commons; Logomarcas das redes sociais; Logomarca dos } \\
\text { indexadores }\end{array}$ \\
\hline
\end{tabular}


Continuação

\begin{tabular}{|c|c|}
\hline Periódicos & Recursos imagéticos \\
\hline $\begin{array}{l}\text { Información, cultura } \\
\text { y sociedad }\end{array}$ & Capa; Indexadores; Logomarca da Licença Creative Commons \\
\hline Enlace & $\begin{array}{l}\text { Agrupamento de perfis dos seguidores; Código de barras do } \\
\text { ISSN; Ícones para redes sociais; Indexadores; Logomarca da } \\
\text { instituição; Logomarca de apoiadores; Logomarca do periódico }\end{array}$ \\
\hline E-Ciencias de la Información & $\begin{array}{l}\text { Indexadores; Logomarca da instituição; Logomarca da Licença } \\
\text { Creative Commons; Logomarca do periódico; Logomarca do } \\
\text { portal de periódicos que está indexada }\end{array}$ \\
\hline Palabra clave & $\begin{array}{l}\text { Bâneres de notícias; Gráfico de visualização em bases de } \\
\text { dados; Ícones das bandeiras dos países para tradução da } \\
\text { escrita do website; Logomarca da Licença Creative Commons }\end{array}$ \\
\hline $\begin{array}{l}\text { Perspectivas em Ciência da } \\
\text { Informação }\end{array}$ & $\begin{array}{l}\text { Capa da edição atual; Logomarca da Licença Creative } \\
\text { Commons; Logomarca do periódico; Logomarcas de bases de } \\
\text { dados e indexadores }\end{array}$ \\
\hline $\begin{array}{l}\text { Revista Interamericana } \\
\text { de Bibliotecología }\end{array}$ & $\begin{array}{l}\text { Capa dos números; Indexadores; Logomarca da instituição; } \\
\text { Logomarca da Licença Creative Commons; Logomarcas das } \\
\text { redes sociais }\end{array}$ \\
\hline $\begin{array}{l}\text { South African Journal of } \\
\text { Information Management }\end{array}$ & $\begin{array}{l}\text { Logomarca do movimento do Acesso Aberto; Logomarca do } \\
\text { periódico; Logomarca dos indexadores }\end{array}$ \\
\hline $\begin{array}{l}\text { South African Journal of } \\
\text { Libraries and Information }\end{array}$ & $\begin{array}{l}\text { Capa do periódico; Logomarca da instituição; Logomarca da } \\
\text { Licença Creative Commons }\end{array}$ \\
\hline $\begin{array}{l}\text { The African Journal of } \\
\text { Information and } \\
\text { Communication }\end{array}$ & $\begin{array}{l}\text { Capa dos números; Logomarca da instituição; Logomarca de } \\
\text { redes sociais; Logomarca do departamento de vinculação; } \\
\text { Vídeos e fotos de pesquisadores e equipe do periódico }\end{array}$ \\
\hline Transinform & $\begin{array}{l}\text { Capa do periódico; Ícones das bandeiras dos países com } \\
\text { idiomas aceitos para publicação no periódico }\end{array}$ \\
\hline
\end{tabular}

Fonte: Dados da pesquisa (2020).

Os dados apresentados no quadro 2 indicam a existência de muitos tipos de recursos imagéticos e que o uso de imagens, pelos periódicos, transcende a mera função de melhoria da arquitetura informacional. Isso porque, as estruturas apresentam-se com pouca coloração, inseridas nas partes laterais, no cabeçalho ou no rodapé do website, despertando, no usuário, o interesse em visitar as abas com os conteúdos dos artigos. Portanto, presume-se que a função desses recursos vai muito além do design, contribuindo, também, na garantia da divulgação do periódico para outros públicos.

A divulgação dos periódicos por meio dos recursos imagéticos, portanto, é um processo que vem crescendo. Desde o desenvolvimento dos primeiros periódicos 
eletrônicos, no Brasil, no início do século XXI, segundo Bomfá e Castro (2004), já se observava o interesse pelo uso das imagens, embora esse interesse estivesse relacionado ao design, haja vista melhorar a estrutura do website. Todavia, no decorrer dos anos, esse interesse se ampliou, sendo direcionado, também, à divulgação científica. Como mencionado no relato de desenvolvimento do primeiro periódico da área de Engenharia de Produção, um dos objetivos desses recursos é "[...] oferecer suporte em mídia digital, facilitando a inserção de artigos e, consequentemente, ampliando a disseminação dos trabalhos científicos [...]”. (BOMFÁ; CASTRO, 2004, p. 41, grifo nosso).

Barcellos (2015) afirma que o uso das imagens entre a comunidade científica constitui uma estratégia para despertar o interesse dos leitores. Assim, autores e editores utilizam as imagens com o fim de "[...] reter a atenção de usuários e leitores assim que as páginas se abrem na tela. Fotografias, bânneres chamativos, títulos fortes, vídeos e gráficos são exemplos de recursos usados, e por vezes exagerados [...]". (BARCELLOS, 2015, p. 1).

O uso de imagens nos websites dos periódicos científicos é uma realidade, sobretudo nas áreas da saúde ou ciências da natureza, como mencionado na pesquisa de Barcellos (2015). Todavia, esse uso tem se expandido para diversas áreas do conhecimento, inclusive na $\mathrm{Cl}$, como constatado no levantamento documental deste estudo. Os recursos imagéticos podem contribuir com os websites dos periódicos, sobretudo por garantir uma melhor visibilidade, captando a atenção e o envolvimento do leitor (BIBLIOTECA DA UNIVERSIDADE DE GEORGETOWN, 2020), além de aumentar a possibilidade de “convencimento" das informações registradas nas mídias. (MARANDINO, 2020).

A análise documental permite inferir que os periódicos utilizam as imagens com diferentes fins: fazer marketing digital e reforçara legitimidade do periódico, tais ações são explicadas a seguir. O marketing digital é uma estratégia de comunicação para despertar a atenção do usuário para acessar o conteúdo dos periódicos, como apontado por Araújo (2015). Já o termo legitimidade do periódico significa que ele é reconhecido, que passou por processos avaliativos, que está vinculado a uma instituição, dentre outras condições que possibilitaram a sua qualificação, validação e reconhecimento.

São várias as estratégias de marketing adotadas pelos periódicos científicos: como a capa dos números das edições, ouso de vídeos com comentários de editores e pesquisadores, dentre outras. Por outro lado, 0 uso da logomarca 


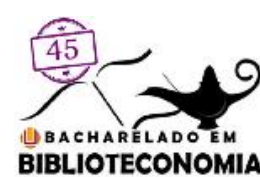

da instituição/departamento e da Licença Creative Commons são recursos utilizados, que aumentam o prestígio e confiabilidade do periódico, tornando-o mais legítimo.

Belz (2017) acredita no potencial das imagens, no processo de divulgação da ciência e, também, afirma que elas precisam ser utilizadas como estratégia de ensino. Com todo efeito, a imagem inserida em um website, seja ela um vídeo, uma figura, um desenho, dentre outras, tem uma função comunicativa, destacando-se, nessa função, a capacidade em "[...] despertar sentidos e apresentar e/ou representar realidades como recursos de persuasão dirigidos aos visitantes dos sites". (ZUTIM, 2009, p. 9).

Com tudo isso, confirma-se a contribuição do uso de objetos não textuais como estratégia de marketing, de comunicação e de visibilidade nos websites dos periódicos científicos. Constata-se, desse modo, a necessidade de melhor aproveitamento desses recursos entre os periódicos da área de $\mathrm{Cl}$.

\section{CONSIDERAÇÕES FINAIS}

Com este estudo, foi possível apresentar um panorama acerca do uso das redes sociais e de recursos imagéticos, como estratégias de divulgação científica pelos periódicos da $\mathrm{Cl}$, considerando seu potencial para a ciência e para a sociedade. Em relação ao uso das redes sociais, alguns pontos foram observados, tais como: a) a maioria dos periódicos investigados utiliza algum tipo de rede social para a divulgação das pesquisas; b) as redes sociais mais utilizadas são o Twitter, o Facebook, - YouTube e o Instagram também são utilizados pelos periódicos, mas em menor proporção. Quanto aos recursos imagéticos, observou-se que todos os periódicos investigados fazem uso de algum tipo de imagem, utilizada com diferentes propósitos, como: melhorar a visualização do site; adquirir recurso de informação para divulgar as pesquisas publicadas; criar estratégia para certificar a qualidade do periódico.

Com tudo isso, pode-se afirmar que os resultados possibilitaram concluir que os periódicos da $\mathrm{Cl}$ podem explorar muito mais a potencialidade das redes sociais e dos recursos imagéticos, com o objetivo de aumentar a visibilidade e o prestígio do periódico junto ao público-alvo. Além disso, este estudo também permitiu identificar outros aspectos, que merecem destaque. São eles: a importância de os periódicos aproveitarem mais o potencial das redes sociais e das imagens, com vistas a ampliar a divulgação científica; e a necessidade de despertar, na comunidade científica, um maior interesse 
em investigar essa temática. Assim, sugerem-se novos estudos teóricos e aplicados, que demonstrem as contribuições desses recursos, no processo de divulgação da ciência.

A partir dos benefícios promovidos com o uso das redes sociais e dos recursos imagéticos, no contexto da divulgação científica nos periódicos, depreende-se que o não uso é uma opção inviável, uma vez que os periódicos deixam de aproveitar o potencial desses recursos no que tange à possibilidade de serem visualizados e reconhecidos, em diferentes partes do mundo, com ampliação do público-alvo. Reforça-se que a visibilidade do resultado das pesquisas é uma necessidade urgente das instituições de pesquisa e uma demanda da sociedade, que carece de compreender a aplicação dos estudos realizados. Além disso, ressalta-se que o alto número de periódicos,surgidos nas últimas décadas, requer a adoção de medidas de divulgação, para garantir a sobrevivência do periódico e a divulgação científica.

\section{REFERÊNCIAS}

ARAÚJO, Ronaldo Ferreira de. Impacto das mídias sociais para revistas científicas da área da saúde. Acta Paulista, São Paulo, v. 32, n. 1, 2019.

ARAÚJO, Ronaldo Ferreira de. Marketing científico digital e métricas alternativas para periódicos: da visibilidade ao engajamento. Perspectivas em Ciência da Informação, Belo Horizonte, v. 20, n. 3, jul./set. 2015.

ARAÚJO, Ronaldo Ferreira de. Marketing científico e métricas alternativas sociais: indicadores-chave de desempenho de periódicos no Facebook. Informação \& Sociedade, v. 28, n. 1, p. 7-22, jan./abr. 2018.

AZEVEDO, Ana Karisse Valença Silva et al. O uso de mídias sociais como marketing digital por revistas científicas eletrônicas da área de Ciências Sociais Aplicadas. In: ENCONTRO DE USUÁRIOS DE SISTEMAS, 1., São Paulo. Anais [...]. São Paulo: SIB/USP, 2017. p. 1-11.

BARCELLOS, Christovam. Uso de imagens nos artigos científicos: visualizar, reter, divulgar, aprender. RECIIS: Revista Eletrônica de Comunicação e Informação, Inovação em Saúde, v. 9, n. 1, jan./mar. 2015.

BELZ, Carlos Eduardo. A fotografia como ferramenta de ensino e de divulgação científica. Revista de Fotografia Ambiental, Rio de Janeiro, v. 1, n. 1, out. 2017.

BIBLIOTECA DA UNIVERSIDADE GEORGETOWN. Usando imagens em publicações. 2020. Disponível em: https://www.library.georgetown.edu/copyright/images-publications. Acesso em: 15 maio 2020.

BOMFÁ, Cláudia Regina Ziliotto; CASTRO, João Ernesto. Desenvolvimento de revistas científicas em mídia digital: o caso da Revista Produção Online. Ciência da Informação, Brasília, v. 33, n. 2, maio/ago. 2004.

BUENO, Wilson Costa. Comunicação científica e divulgação científica: aproximações e rupturas conceituais. Informação \& Informação, Londrina, v. 15, p. 1-12, 2010.

CABRÉ, Maria Teresa. La terminología hoy: concepciones, tendencias y aplicaciones. Ciência da Informação, Brasília, v. 24, n. 3, 1995. 
CARIBÉ, Rita de Cássia do Vale. Comunicação científica: reflexões sobre o conceito. Informação \& Sociedade: Estudos, João Pessoa, v. 25, n. 3, p. 89-104, set./dez. 2015.

COSTA, Luciana Ferreira da et al. O uso de mídias sociais por revistas científicas da área da Ciência da Informação para ações de marketing digital. Revista ACB: Biblioteconomia em Santa Catarina, Florianópolis, v. 21, n. 2, p. 338-358, abr./jul. 2016.

FONSECA JÚNIOR, Wilson Corrêa da et al. A avaliação biblioemétrica de instituições de pesquisa para além da comunicação científica: o caso Embrapa. BiD, n. 43, dez. 2019.

FRIGERI, Monica. SciELLO: 15 anos de parceria com os periódicos científicos. Ciência e Cultura, v. 66, n. 1, 2014.

GIL, Antônio Carlos. Métodos e técnicas de pesquisa social. 7. ed. São Paulo: Atlas, 2019.

GODEIRO, Rebeka Maria de Carvalho Santos; SERAFIM, Andreza Nadja Freitas. Instrumentos de colaboração e produção de conhecimento, que recomenda, qualifica e dissemina a informação no âmbito da web. In: CONGRESSO BRASILEIRO DE BIBLIOTECONOMIA E DOCUMENTAÇÃO, 25., Florianópolis. Anais [...]. Florianópolis: FEBAB, 2013. p. 1-12.

KURAMOTO, Hélio. Informação científica: proposta de um novo modelo para o Brasil. Ciência da Informação, Brasília, v. 35, n. 2, jul./dez. 2006.

LE COADIC, Yves-François. A ciência da informação. 2 ed. Brasília: Briquet de Lemos, 2004. LOPES, Bianca da Costa Maia. Popularizar ou perecer: a potencialidade informacional dos arquivos na internet. 2018. 147f. Dissertação (Mestrado em Ciência da Informação) - Escola de Comunicação, Universidade Federal do Rio de Janeiro, Rio de Janeiro, 2018.

MARANDINO, Martha. $O$ uso das imagens na ciência, no ensino e na divulgação da ciência. 2020. Disponível em: http://www.univates.br/revistas/index.php/cadped/article/viewFile/869/858. Acesso em: 15 maio 2020.

MONERAT, Carlos Alberto Andrade; ROCHA, Marcelo Borges. Como as revistas de divulgação científica utilizam os recursos imagéticos em textos sobre Biologia Celular. Acta Scientiae, Canoas, v. 19, n. 6, nov./dez. 2017.

MURIEL-TORRADO, Enrique; GONÇALVES, Marcio. Youtube nas bibliotecas universitárias brasileiras: quem, como e para o que é utilizado. Pesquisa Brasileira em Ciência da Informação, v. 13, n. 1, 2018.

PRÍNCIPE, Eloisa. Redes sociais e a comunicação científica. In: ALBAGLI, Sarita (Org.).

Fronteiras da ciência da informação. Brasília: IBICT, 2013.

RIBEIRO, Sara Dieny Chaves; SILVA, Merielem Frasson da. Uso da rede social Instagram como ferramenta de marketing da informação em Biblioteca Pública Especializada. In: CONGRESSO BRASILEIRO DE BIBLIOTECONOMIA E DOCUMENTAÇÃO, 28., Vitória. Anais [...]. Vitória: FEBAB, 2019. p. 1-5.

SANTANA JÚNIOR, Célio Andrade et al. A disseminação da informação no Twitter: uma análise exploratória do fluxo informacional de retweets. Ato Z, Curitiba, v. 3, n. 1, 2014.

SANTOS, Ana Claudia de Araujo; ALVES, Edvaldo Carvalho; OLIVEIRA, Henry Pôncio Cruz de. O conceito de informação imagética na ciência da informação: aproximações teórico-conceituais. Em Questão, v. 25, n. 2, p. 39-65, 2019. Disponível em: www.brapci.inf.br/index.php/res/v/113841. Acesso em: 14 maio 2020.

SHIMIZU, Heitor. Uso das mídias sociais na ciência. Agência FAPESP, São Paulo, fev. 2013.

SOUZA, Uarlens de Jesus et al. O uso das redes sociais pelos periódicos brasileiros de Biblioteconomia e Ciência da Informação. Revista ACB, Florianópolis, v. 20, n. 3, p. 584-591, set./dez. 2015.

TARGINO, Maria das Graças; TORRES, Názia Holanda. Comunicação Científica Além da Ciência. Ação Midiática: Estudos em Comunicação, Sociedade e Cultura, [S.I.], jul. 2014. 
TOMAÉL, Maria Inez. Redes sociais, conhecimento e inovação localizada. Informação \& Informação, Londrina, v. 12, p. 1-24, 2007.

VICENTE, Natalí llza; CORRÊA, Elisa Cristina Delfini; SENA, Tito. A divulgação científica em redes sociais na internet: proposta de metodologia de análise netnográfica. In: ENCONTRO NACIONAL DE PESQUISA EM CIÊNCIA DA INFORMAÇÃO, 16., João Pessoa. Anais [...]. João Pessoa: ANCIB, 2015. p. 1-20.

ZUTIM, Sueli. Notícia virtual: um olhar sobre a linguagem imagética. 2009. 105f. Dissertação (Programa de Pós-Graduação e Educação) - Instituto de Biociência, Universidade Paulista Júlio de Mesquita Filho, Rio Claro, 2009.

Agradecimentos: Os autores agradecem à Coordenação de Aperfeiçoamento de Pessoal de Nível Superior (CAPES) pelo financiamento desta pesquisa. 